\title{
Imperiling on Urban Environment by Air Pollution and its Impact on Human Health
}

\author{
Durdana Rais Hashmi ${ }^{a *}$, Akhtar Shareef ${ }^{a}$, Muhammad Azamb and Talha Rehan Qadria \\ ${ }^{a}$ Centre for Environmental Studies, PCSIR Laboratories Complex, Karachi-75280, Pakistan \\ ${ }^{b}$ Department of Geography, Federal Urdu University of Arts, Science and Technology, Karachi, Pakistan
}

(received April 4, 2018; revised September 28, 2018; accepted October 10, 2018)

\begin{abstract}
Present study was carried out to analyze the concentration of the pollutants due to air born particulate matter $\left(\mathrm{PM}_{10}\right)$ and infectious trace gases and their effects on human health at ten different locations along busy intersections in the commercial, residential and industrial areas of Karachi city. At each selected location, the study was carried out to determine the level of particulate matter and trace gases for a period of $8 \mathrm{~h}$ twice in a month during the year 2015. Samples were collected at ten selected locations i.e. Karimabad(C-1), Tibet Centre(C-2), and Liaquatabad(C-3) in commercial areas; PIB Colony(R-1), Nazimabad(R-2) and Gulshan-e-Iqbal(R-3) in residential areas; Siemens G. Belt(I-E1), Naurus G Belt (I-E2), Singer Chowrangi(I-W3) and Chamra Chowrangi(I-W4) in industrial areas of the city. Results received from different air quality categories were calculated according to National Environmental Quality Standard (NEQS) at selected locations, as in commercial areas showing poor pollution level for trace gases and $\mathrm{PM}_{10}$ due to high traffic density. In Residential areas PIB Colony (R-1) and Gulshan-e-Iqbal (R-3), found under good category with respect to the trace gases and moderate pollution level for the $\mathrm{PM}_{10}$ pollution, having low traffic density whereas Nazimabad(R-2) presents moderate category for trace gases and unhealthy category for $\mathrm{PM}_{10}$ pollution with high traffic density. In industrial areas Singer Chowrangi (I-W3) and Chamra Chowrangi(I-W4) found under moderate pollution level with moderate traffic density, whereas, Siemens G. Belt(I-E1) and Naurus G. Belt(I-E2) locations are represented by moderate pollution values for trace gases and found under poor pollution level for $\mathrm{PM}_{10}$ pollution, may be due to industrial emissions and heavy vehicular emission. Level of $\mathrm{PM}_{10}$ and trace gases at all the selected sites excluding residential areas, exceeds the permissible limits as specified by NEQS.
\end{abstract}

Keywords: ambient air, particulate matter, trace gases, health hazards

\section{Introduction}

Air pollution has become a global issue and causing massive health hazards, climatic changes, metrology and ecology of the environment. These days air pollution is well-known to be significantly aggravated by infectious atmospheric trace gases, liquid droplets and suspended solid particles (Kaldellis et al., 2012), that may be directly emitted (primary pollutants) and/or formed into the atmosphere (secondary pollutants). Primary pollutants emitted directly into the air both from human activities (e.g. agricultural activities, power plants, industrial processes, combustion of fossil fuels, burning of biomass, construction and demolition activities etc.) and from natural processes (e.g. plants' photo synthesis, forest fires, volcanic eruptions etc.). Whereas secondary pollutants, such as ground level ozone, not emitted directly but are formed into the atmosphere when primary pollutants react chemically with one another or with natural component of atmosphere (Saho et al., 2017). In Pakistan ambient air quality has *Author for correspondence; E-mail: drhpakr@yahoo.com increasingly deteriorated due to anthropogenic sources like industrialization, unplanned urbanization, rapid growth of population, open burning of waste and vehicular emission due to poor transportation system. For many decades scientist and researchers have provided undeniable data that the emission and deposition of air pollutants damage the life and quality of plants and animals, quality of water, degraded the soil, productivity of forest and hazards for human health. Modernization and industrialization are main factors responsible for environmental damage particularly in rapidly growing mega cities. Air pollution is a hot issue in most of the mega cities of the world especially in developing countries due to high rate of rural urban migration. The proportion of the world urban population living in the large towns or cities has grown about two thirds of humanity during past two decades. Demographers estimate that by the year 2050, 6.4 billion people become urban residents, approximately two third of the world population will live in large towns or cities (Amera, 2015). 
Particulate matter of 10 microns aerodynamic diameter $\left(\mathrm{PM}_{10}\right)$ is one of the most important issue in urban cities, not only affect the status of cultural heritages, particularly affecting the pulmonary system, it can penetrate deep into the lungs and cause respiratory disorder and increased incidence of bronchitis, chronic cough and conjunctivitis (Raina et al., 2014). Furthermore, clinical and epidemiological studies indicating that air pollution not only associate with pulmonary disorder but also with cardiovascular disorders. Patho-physiological studies show that elevated concentration of inhalable particulate $\left(\mathrm{PM}_{10}\right)$ is related with mortality and morbidity due to lungs and heart function disorders (Brook et al., 2010). If fine particles contain materials the chemical reaction with material in human body system may cause pneumoconiosis and silicosis. If it contains hydrocarbon etc., resulting in deadly diseases such as cancer (Curtis et al., 2006). When particulate matter deposited on the surface of the leaves it blocks the pores or stomata which reduces the reaction of photosynthesis (absorption of sunlight and $\mathrm{CO}_{2}$ from the atmosphere) and also effects on the growth of plants.

Inhalation of different types of air pollutants with short term and long term exposure can lead to various hazards effects on human body organ system and can vary from nausea, difficulty in breathing, skin irritation to cancer. Health effects of air pollutants also contain birth defects, serious developmental delays in children, reduced activity of the immune system, leading to a number of diseases and can also be distinguished to both acute and chronic effects on human health conditions (Marilena and Elias, 2008). Model data indicated that in children primarily affected system is respiratory system ranging from minor upper respiratory irritation to chronic respiratory infections whereas, cardiovascular diseases, bronchitis, pulmonary disorder and asthmic attacks in adults are also reported (Samoli et al., 2011).

Besides particulate matter, literature also suggests that there is a strong relationship between higher concentrations of sulphur dioxide $\left(\mathrm{SO}_{2}\right)$, nitrogen dioxide $\left(\mathrm{NO}_{2}\right)$ and carbon monoxide $(\mathrm{CO})$ that may exaggerate several health effects (Annunziata et al., 2014). The source of $\mathrm{NO}_{2}$ into the atmospheric air are various natural and anthropogenic activities. The most important and major anthropogenic source is the combustion of fossil fuel in motor vehicle engines. It creates several toxicological problems. Common adverse health complications of nitrogen oxides are bronchitis, coughing and wheezing whereas ENT irritation, chest pain, headache, dyspnea, diaphoresis, bronchospasm and pulmonary edema may also occur.

$\mathrm{SO}_{2}$ is very harmful for human, animals and for plant life. The major health issues associated with high concentrations of $\mathrm{SO}_{2}$ exposure causes respiratory irritation, dysfunction and cardiovascular disease. Children and older people are at higher risk of skin diseases and pulmonary disorder.

Carbon monoxide is one of the major air pollutants in metropolitan cities. In the congested part of cities where traffic jams usually occurs, this pollutant show high concentration and producing serious problems on human health. $\mathrm{CO}$ is a poisonous gas and its symptoms may include headache, tiredness, dizziness, nausea, vomiting and drowsiness and in very acute situation consciousness and death will follow (Malakootian and Yaghmaeian, 2004). The affinity of CO to hemoglobin (as an oxygen carrier in the body) is about 250 times greater than that of oxygen. The effect of $\mathrm{CO}$ on human being depend on the concentration, exposure time, health status of the people, their age and daily activities (Ghorani et al., 2016).

Aim of this study was to determine the level of atmospheric trace gases such as sulphur dioxide $\left(\mathrm{SO}_{2}\right)$, carbon monoxide $(\mathrm{CO})$, nitrogen dioxide $\left(\mathrm{NO}_{2}\right)$ and particulate matter $\left(\mathrm{PM}_{10}\right)$ in the environment of Karachi city for the year of 2015. This study explained the range of air quality and its relation to health hazards to provide awareness in the society.

\section{Materials and Methods}

Study area. Karachi is located in a semi arid zone on the coast of the Arabian Sea. It has an area of 3,640 $\mathrm{km}^{2}$ and lies between long $67^{\circ}$ east, lat $25^{\circ}$ north. It is also a sea shore and a busy port encountering both the sea and land breeze periodically. Due to industrialization, business activities and employment opportunities Karachi has been facing mass scale rural-urban migration from all over Pakistan (Sajjad et al., 2010). Karachi has a moderately temperate climate with a generally high relative humidity that varies from $58 \%$ in December (the driest month) to $85 \%$ in August (the wettest month). In winter, the average temperature of the city is about $21^{\circ} \mathrm{C}$ while in summer it reaches up to $35^{\circ} \mathrm{C}$. Karachi receives about $256 \mathrm{~mm}$ of average annual rainfall (Sajjad et al., 2010).

Many fold increase in vehicles on poorly maintained roads and insufficient road spaces, less parking facilities, 
encroachment on road and footpath and violation of traffic rules with an alarming traffic management strategy are main issues of urban air pollution. Approximately, $70 \%$ of the total aerial pollution load in Karachi is mainly produced by vehicular emission. Mushroom growth in automobiles have brought the wake of air quality degradation and health issues up to alarming level. The two and three wheelers petrol-driven vehicles emit carbon monoxide $(\mathrm{CO})$, particulate matter $\left(\mathrm{PM}_{10}\right)$ and large quantities of un-burnt hydrocarbons. In the city of Karachi means of transport are public and private buses, vans and auto-rickshaws. As most of the private buses on the roads are very old and out dated, emitting high concentration of pollutants than the permissible limits. According to the annual vehicle statistics 2017, 961,842 registered motor vehicles are plying on the roads of Karachi (LTA, 2017).

Karachi has also a well defined industrial base, such as Sindh Industrial Trading Estate (SITE), Korangi Industrial Area (KIA), Landhi Industrial Trading Estate (LITE), Northern By-pass Industrial area, Karachi Export Processing Zone, Bin Qasim and North Karachi Industrial Estate, located in the boundary of the city. Its primary industries are textiles, pharmaceuticals, steel, and automobiles.

Methodology. Sampling was carried out at ten different locations in Karachi during the year 2015 for gaseous pollutants and particulate matter. Selected locations were striking as commercial(C), residential(R) and industrial (I) areas of the Karachi's environment. These monitoring locations were selected on main roads and round-about surrounded by heavy traffic intersections. Locations were selected on a random basis. The details of the monitoring locations are given in Table 1.

The sampling was conducted twice in a month from October to December in winter season and April to June in summer season during the year 2015. Air samples were collected for $08 \mathrm{~h}$ in a day.

Monitoring of $\mathbf{P M}_{10}$. Analysis had been carried out by using hi-volume air sampler installed by Centre for Environmental Studies, PCSIR Laboratories Complex, Karachi. $\mathrm{PM}_{10}$ samples were collected on glass fibre filters $(203 \times 254 \mathrm{~mm})$ with an average flow rate of 1.0 $\mathrm{m}^{3} / \mathrm{min}$. $08 \mathrm{~h}$ sampling was done in duplicate at each location during the year of 2015. The high volume air sampler is considered a reliable sampler for measuring the mass of $\mathrm{PM}_{10}$ in ambient air (USEPA-Method 40 CFR).

Samples of particulate matter $\left(\mathrm{PM}_{10}\right)$ have been collected from the selected locations season-wise during April to June in summer season and October to December in winter season for the year of 2015 according to USEPA method No. US 40 CFR.

Monitoring of trace gases. CO gas analyzer (Model 50). Snifit CO Analyzer (Model 50) was used to collect

Table 1. Description of the sampling locations during the study period in Karachi

\begin{tabular}{|c|c|c|}
\hline Locations & Code \# & Activities \\
\hline $\begin{array}{l}\text { Karimabad } \\
\text { Tibet Centre } \\
\text { Liaquatabad }\end{array}$ & $\begin{array}{l}\mathrm{C}-1 \\
\mathrm{C}-2 \\
\mathrm{C}-3\end{array}$ & Vehicular emission due to high traffic density and high commercial activities. \\
\hline PIB Colony & $\mathrm{R}-1$ & $\begin{array}{l}\text { Moderate traffic density, exposed dump/exposed pit surface, domestic waste } \\
\text { burning and residential activities. }\end{array}$ \\
\hline Nazimabad & $\mathrm{R}-2$ & $\begin{array}{l}\text { Heavy traffic density with transport on paved road and unpaved road, haul road } \\
\text { and exposed dump/exposed pit surface, domestic waste burning and residential } \\
\text { activities. }\end{array}$ \\
\hline Gulshan-e-Iqbal & $\mathrm{R}-3$ & Average traffic density, domestic waste burning and residential activities. \\
\hline Siemens G Belt & $\mathrm{I}-\mathrm{E} 1$ & $\begin{array}{l}\text { Vehicular emission due to heavy traffic density. Industrial emission due to Stack } \\
\text { emissions from boilers, generators, incinerators and other industrial activities. }\end{array}$ \\
\hline Naurus G Belt & $\mathrm{I}-\mathrm{E} 2$ & \\
\hline Singer chowrangi & $\mathrm{I}-\mathrm{W} 3$ & $\begin{array}{l}\text { Vehicular emission due to moderate traffic density. Industrial emission due to Stack } \\
\text { emissions and other industrial activities. }\end{array}$ \\
\hline Chamra chowrangi & $\mathrm{I}-\mathrm{W} 4$ & \\
\hline
\end{tabular}


the data for the concentration of carbon monoxide. This analyzer is ideal for measuring the carbon monoxide at ppm level. For collecting the data from ambient air this snifit analyzer was kept at about $1.2 \mathrm{~m}$ above the ground level. The concentrations of $\mathrm{CO}$ was noted at an interval of $2 \mathrm{~min}$ and a set of triplicate readings was noted at each interval.

UV fluorescent $\mathrm{SO}_{2}$ analyzer (Model AF22 M). Sulphur dioxide (AF22M) model analyzer capable of measuring sulphur dioxide up to the ppb level was applied for $\mathrm{SO}_{2}$ measurement. The universally known UV fluorescent principle consists in detecting the characteristic fluorescence radiation emitted by $\mathrm{SO}_{2}$ molecules. In the presence of a specific wavelength of UV light (214 nm) the $\mathrm{SO}_{2}$ molecules reach temporary excited electronic state. The subsequent relaxation produces a florescence radiation which is measured by a non-cooled photomultiplier tube (PM).

NO-NOx analyzer (Model AC 32M). The Chemiluminescent $\mathrm{NO}-\mathrm{NO}_{2}-\mathrm{NO}_{\mathrm{X}}$ analyzer, model AC32M, capable of measuring nitrogen oxides at ppb levels was applied for nitrogen oxides measurement. Chemiluminescence corresponds to an oxidation of NO molecules by $\mathrm{O}_{3}$ molecules. The return to a fundamental electronic state of the excited $\mathrm{NO}_{2}$ molecules is made by luminous radiation, detected by the PM tube. The model AC32M is a state-of-the-art single chamber-single photomultiplier tube design which automatically cycles between the $\mathrm{NO}$ and $\mathrm{NO}_{\mathrm{X}}$ modes. The new electronics system allow to enhance the data storage capacity for more than one month of $15 \mathrm{~min}$ averages and total remote troubleshooting diagnostic capabilities via a modem.

\section{Results and Discussion}

The mean $\mathrm{PM}_{10}$ recorded concentration of ambient air monitoring locations during winter season from the month of October to December varied from $120 \mu \mathrm{g} / \mathrm{m}^{3}$ (at location R-3) to $274 \mu \mathrm{g} / \mathrm{m}^{3}$ (at location I-E1) with an overall mean concentration of $209.2 \mu \mathrm{g} / \mathrm{m}^{3}$. Whereas, during summer season from the month of April to June varied from $97 \mu \mathrm{g} / \mathrm{m}^{3}$ (at location R-3) to $228 \mu \mathrm{g} / \mathrm{m}^{3}$ (at location $\mathrm{C}$-2) with an overall mean concentration of $168.3 \mu \mathrm{g} / \mathrm{m}^{3}$. The $\mathrm{PM}_{10}$ concentration exceeded the permissible limit of $150 \mu \mathrm{g} / \mathrm{m}^{3}$ specified by National Environmental Quality Standard (NEQS) at all the locations except location R-3. The season-wise mean $\mathrm{PM}_{10}$ calculated results are presented in Fig.1-2.
$\mathrm{NO}_{2}$ observed concentration in winter season (October to December) was found to be minimum at location R$3\left(67 \mu \mathrm{g} / \mathrm{m}^{3}\right)$ and maximum at location C-2 $\left(143 \mu \mathrm{g} / \mathrm{m}^{3}\right)$ with overall average of $106.8 \mu \mathrm{g} / \mathrm{m}^{3}$. Whereas, during summer season from the month of April to June varied from $38 \mu \mathrm{g} / \mathrm{m}^{3}$ (at location R-1) to $109 \mu \mathrm{g} / \mathrm{m}^{3}$ (at location I-E1) with an overall mean concentration of $81.1 \mu \mathrm{g} / \mathrm{m}^{3}$. Except at the location R-3, $\mathrm{NO}_{2}$ concentration level exceeded the allowable limit of $80 \mu \mathrm{g} / \mathrm{m}^{3}$ specified by NEQS in winter season whereas, in summer season $\mathrm{NO}_{2}$ concentration exceeded the allowable limit of NEQS except the selected locations in residential areas as R-1, R-2 and R-3. Season-wise variation of $\mathrm{NO}_{2}$ presented in Fig. 3-4.

$\mathrm{SO}_{2}$ concentration during winter season ranged between $24 \mu \mathrm{g} / \mathrm{m}^{3}$ (at R-3) and $89 \mu \mathrm{g} / \mathrm{m}^{3}$ (at I-E2) with overall average value of $56.6 \mu \mathrm{g} / \mathrm{m}^{3}$, in summer season ranged between $15 \mu \mathrm{g} / \mathrm{m}^{3}$ (at R-3) and $82 \mu \mathrm{g} / \mathrm{m}^{3}$ (at C-2) having overall average $42.1 \mu \mathrm{g} / \mathrm{m}^{3}$ with respect to the allowable limit of $120 \mu \mathrm{g} / \mathrm{m}^{3}$. Season-wise $\mathrm{SO}_{2}$ concentrations are presented in Fig. 5-6.

The $\mathrm{CO}$ mean concentration during winter season was found to be minimum at location R-3 $\left(1.4 \mu \mathrm{g} / \mathrm{m}^{3}\right)$ and maximum at location I-E2 $\left(4.9 \mu \mathrm{g} / \mathrm{m}^{3}\right)$ with the average of $3.31 \mu \mathrm{g} / \mathrm{m}^{3}$. The range of $\mathrm{CO}$ in summer season varies from $0.8 \mu \mathrm{g} / \mathrm{m}^{3}$ (at R-3) to $3.7 \mu \mathrm{g} / \mathrm{m}^{3}$ (at C-2) with the average of $2.5 \mu \mathrm{g} / \mathrm{m}^{3}$. The permissible NEQS limit of $\mathrm{CO}$ is $10 \mu \mathrm{g} / \mathrm{m}^{3}$. Season-wise results of $\mathrm{CO}$ concentration are presented in Fig. 7-8.

In general, the average concentration of trace gases and $\mathrm{PM}_{10}$ was found at maximum level in commercial and industrial sampling sites having high traffic congestion than residential sites. At most of the selected sampling sites concentrations of the pollutants exceeded the specified permissible limits set by the NEQS. The highest mean concentrations of $\mathrm{PM}_{10}$ and trace gases were observed at C-2 followed by I-E1 and I-E2. Location C-2 is in the category of commercial area having high-rise buildings, diverse types of offices, tea and coffee shops, dhaba hotels, restaurants and food items push cart producing high concentration of pollutant due to traffic congestion and commercial activities whereas, location I-E1 and I-E2 are situated in Sindh Industrial Trading Estate surrounded by industrial cluster on both faces of the roads. These sites also exhibited high traffic congestion mainly due to heavy duty diesel vehicles i.e. trucks, tractors, trailers, vans, buses and 


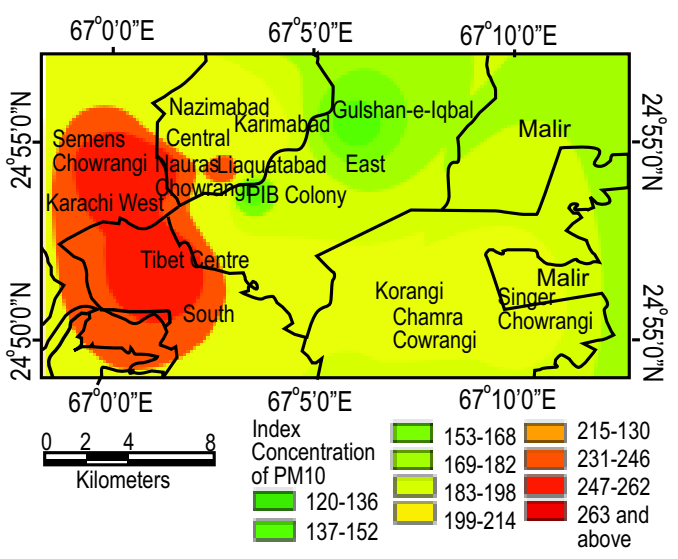

Fig. 1. Pollution load of $\mathrm{PM}_{10}$ at the selected locations during winter season.

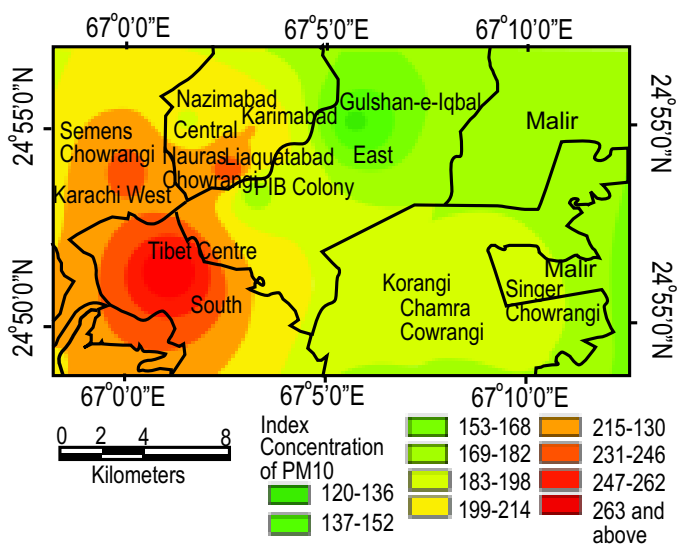

Fig. 3. Pollution load of $\mathrm{NO}_{2}$ at the selected locations in winter season.

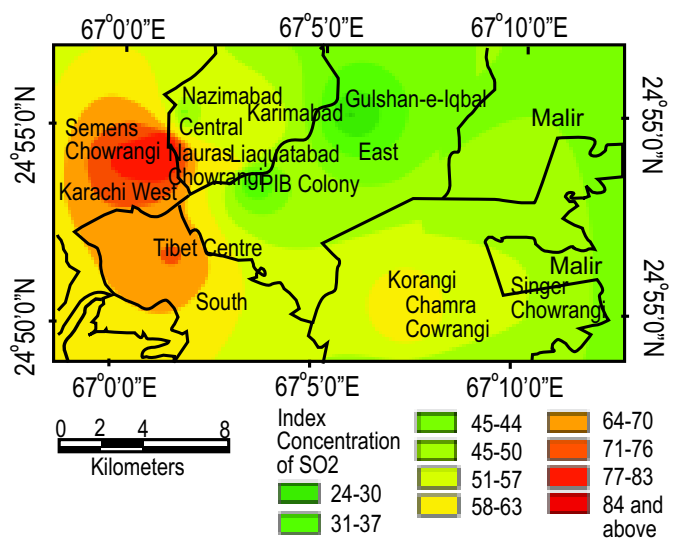

Fig. 5. Pollution load of $\mathrm{SO}_{2}$ at the selected locations in winter season.

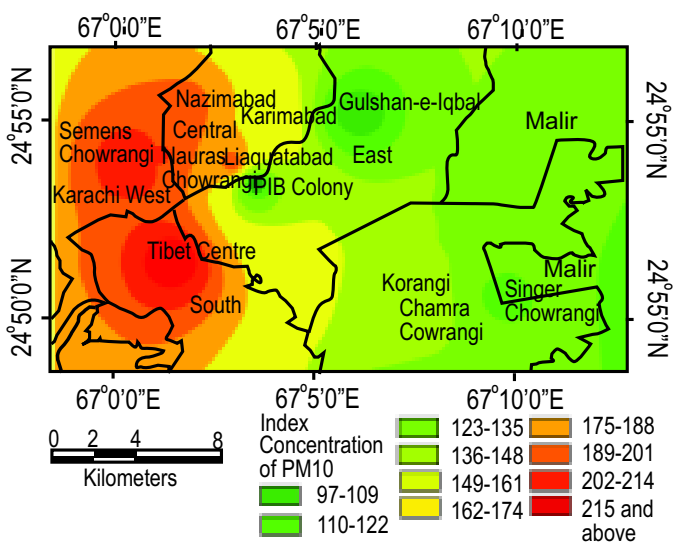

Fig. 2. Pollution load of $\mathrm{PM}_{10}$ at the selected locations during summer season.

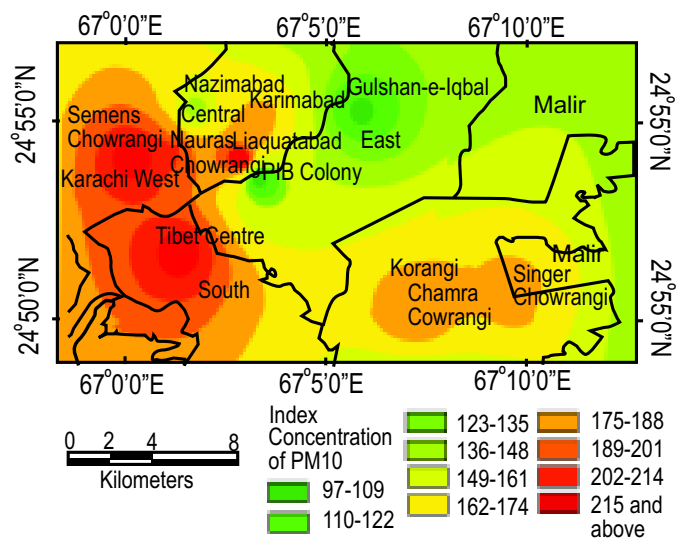

Fig. 4. Pollution load of $\mathrm{NO}_{2}$ at the selected locations in summer season.

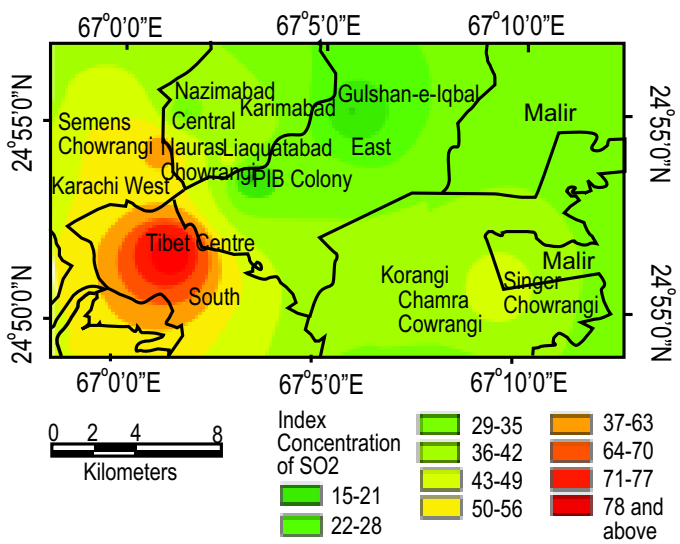

Fig. 6. Pollution load of $\mathrm{SO}_{2}$ at the selected locations in summer season. 


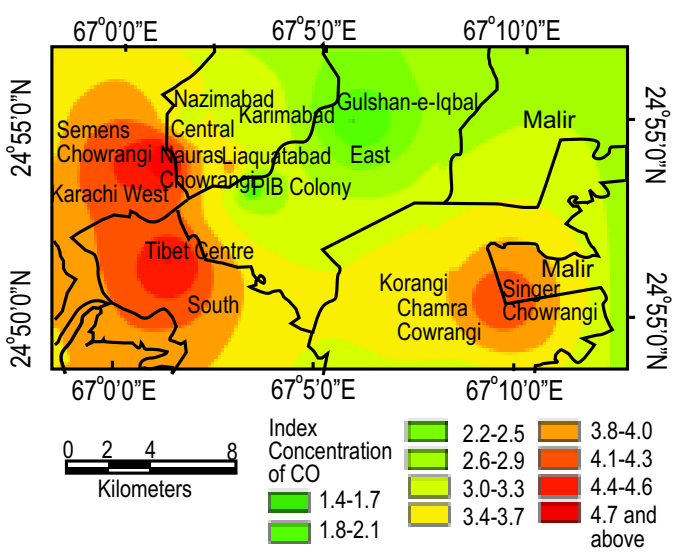

Fig. 7. Pollution load of $\mathrm{CO}$ at the selected locations during winter season.

minibuses. Moreover, at these locations roads are also poorly maintained, unpaved and dusty with limited vegetation along the sides. The industrial processes especially combustion boilers fueled by heavy duty diesel, and heavy electric generators also fueled by diesel are the main source of $\mathrm{PM}_{10}$ pollution and trace gases emission. As location C-2 surrounded by high rise buildings producing tunnel effects, the pollutants are suspended for long time and it is associated with potential health effects for the residents especially for infant and old age group/sensitive residents. The study found that there are high levels of particulate matter concentration across all the locations. The pragmatic results of $\mathrm{PM}_{10}$ concentration may be due to both vehicular emission and industrial emission. Motor vehicle emission exhausts dispersed up to long range distance and damage the mechanism of respiratory system that causes the adverse chemical changes in human body system which may reduce lung capacity.

A number of clinical studies show strong association between respirable particulate $\left(\mathrm{PM}_{10}\right)$ with the increase in the number of mortality and morbidity (Brook et al., 2010).

According to the reported WHO (2012) the ambient air quality contributed to 3.7 billion premature deaths globally, accounting for $80 \%$ of premature deaths (defined as early end of individual life before expected age). Moreover, in 2014 WHO reported that globally $14 \%$ of Chronic Obstruction Pulmonary Diseases (COPD) related deaths and acute lower respiratory infections and $6 \%$ of lung cancer related deaths were

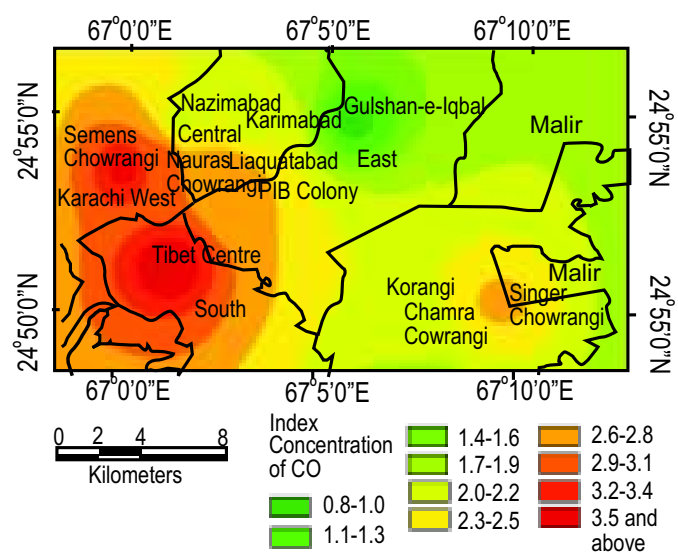

Fig. 8. Pollution load of $\mathrm{CO}$ at the selected locations during summer season.

attributed to poor air quality. Developing countries are reported to suffer more from particle pollution, probably due to the lack of control measures and lack of efforts to monitor and control pollution at the point of generation (Ndinomholo and Caryl, 2017).

Impact on human health. This study was aimed to determine the air pollution exposure and health hazards for the resident of selected commercial, residential and industrial areas. The target group of this study classified as they reside in high exposure areas, duration of exposure, nature of job, age group and their way of living. People that exposed up to high enough levels of atmospheric pollutants may experience: (a) Irritation of the eyes, nose, and throat; (b) coughing, wheezing, bronchitis, nose irritation, chest infection and other breathing problems; (c) worsening of existing pulmonary difficulties such as asthma.

A questionnaire survey was arranged to collect the health associated data from the population of exposed areas.

The following steps have been taken in this study.

- Filling of the questionnaires from 223 inhabitants (109 from commercial areas, 46 from residential areas and 68 from industrial areas) about their health conditions.

- Interviews of the private clinical doctors, government and private hospitals doctors, and effectees of the concerned areas were conducted.

- Empirical relations from this data were calculated with respect to the particulate matter and trace gases. 
- By using the empirical relations percentages of the effectees were also calculated during the study.

The data collected from this onset survey were calculated to evaluate the percentage of health risk with reference to pulmonary disorder patients and causing factors for this problem in selected areas. The data collected from questionnaires filled by the residents ( 223 residents) in commercial, residential and industrial areas indicated that $6.5 \%$ had developed cardiac problems, $6.9 \%$ lungs problem, $7.6 \%$ pneumonia, $8.1 \%$ emphysema, $8.9 \%$ wheezing, $12.5 \%$ bronchitis, $13.4 \%$ nose irritation, $14.7 \%$ sneezing, $17.4 \%$ coughing and $24.6 \%$ asthma, respectively during winter season. Whereas, 5.9\% had developed cardiac problems, $6.2 \%$ lungs problem, $6.9 \%$ pneumonia, $7.7 \%$ emphysema, $8.1 \%$ wheezing, $8.7 \%$ bronchitis, $9.6 \%$ nose irritation, $11.3 \%$ sneezing, $13.2 \%$ coughing and $16.7 \%$ asthma in summer season respectively, presented in Fig. 9-10, respectively.

Figures 9-10 showing the correlation between average air pollution (i.e. the average of TSP, CO, NO and SO) recorded in winter season (Fig. 9) and summer season (Fig. 10) of 2015 and the number of patients (in percentage) revealed that highly positive correlation was found between them (i.e. $\mathrm{R}=0.85$ and $\mathrm{R}=0.90$, respectively). It means dirty air pollution can impair breathing and aggravate various lung diseases. The result have been confirmed by Chauhan and Johnston (2003) who reported that air pollution is associated with adverse health outcome particularly respiratory diseases/infections (Chauhan and Johnston, 2003).

Results of this study show that average health situation has close linkage with atmospheric pollutants path ways

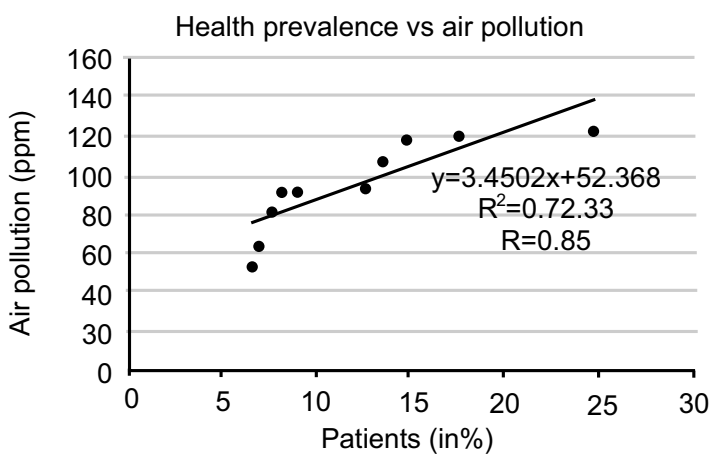

Fig. 9. Health prevalence vs. air pollution during winter season in Karachi. and population. The infants, elders and the persons who suffer with chronic pulmonary diseases, influenza or asthma are at the risk of mortality and serious morbidity effects while others are in danger for health effects such as increase in respiratory diseases, disorders in lung functions and changes in physiology of human body system.

As Karachi city is one of the largest and densely populated city in the province of Sindh, having regional trade, public administration, education communication and transportation core. Shopping centers, offices for business, medical centers, agricultural and educational institutes, industrial zones, commercial and residential areas are located too close that sometimes mixed together and make the environment more complicated. It was found that almost all types of pollution related diseases were found in almost all the selected areas and causing serious health hazards.

Mitigation of urban air pollution. Air pollution is a global problem over major cities all over the world. Parallel to other mega cities of the world level of air quality in Karachi, Pakistan is worsening day by day. Motor vehicle emission and industrial activities are responsible for air pollution problem. For mitigation of air pollution:

- Restrictive emissions from both industry and transport sector will be required.

- Encouraging the Industries to shift outside the residential areas.

- Enforced the industrialist to maintain the condition of machinery (boilers, generators, incinerators) to minimize the emission in ambient air.

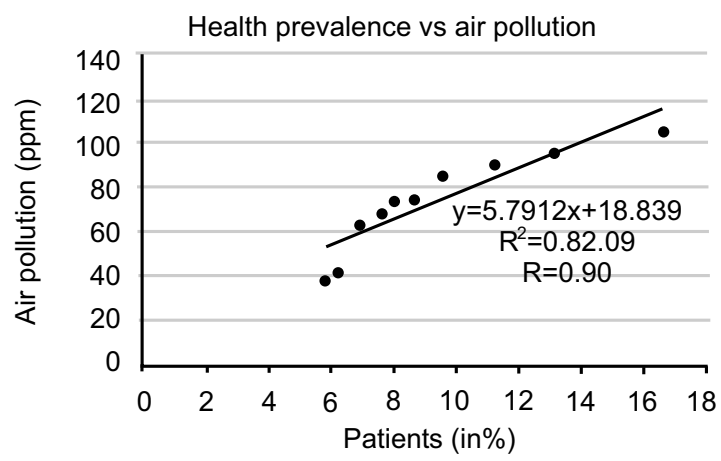

Fig. 10. Health prevalence vs. air pollution during summer season in Karachi. 
- Enforced the Government for replacing the old vehicles on the roads of the city.

- Aware the citizens for maintaining the in-use vehicles properly.

- Educate the citizens to use the catalytic converter in the vehicles that reduce the emission level.

- Improving the condition of roads and road design.

- Organizing the traffic management system to control the traffic jams on the roads.

- Justification for health benefits should include and make public awareness seminars and workshops in school, colleges and universities, also aware the ill-literate citizens by flowing the aids on TV channels to control or minimize the pollution in the city.

\section{Conclusion}

It can be concluded that Karachi is found to be in a dreadful situation due to air pollution problem. Results of this study show that the concentrations of pollutants exceeding the permissible limits in commercial areas, industrial areas and in the residential areas, having both commercial and residential activities. The main source of air pollution appears to be the emission from ill planned traffic congestion and industrial activities. Results of this study also reveal that high concentration of pollution may cause negative impact on the atmospheric environment and potential health hazards to the residents of the city. Government and local bodies should take immediate measures, planning and social awareness to reduce the pollution load and improving the status of air quality in the city.

Conflict of Interest. The authors declare no conflict of interest.

\section{References}

Amera, A. 2015. Imperiling urban environment through varying air pollution rein in measures and mass transit policies - A case study of Lahore. Technical Journal, University of Engineering and Technology (UET) Taxila, Pakistan, 20: 67-73.

Annunziata, F., Regula, R., Francesco, F. 2014. Nitrogen dioxide and mortality: review and meta-analysis of long-term studies. The European Respiratory Journal, 44: 744-753.

Brook, R.D., Rajagopalan, S., Pope, C.A., Brook, J.R., Bhatnagar, A., Diez-Roux, A.V., Holguin, F., Hong, Y., Luepker, R.V., Mittleman, M.A., Peters, A.,
Siscovick, D., Smith, S.C., Whitsel, L., Kaufman, J.D. 2010. Particulate matter air pollution and cardiovascular disease: an update to the scientific statement from the American Heart Association. Circulation, 121: 2331-2378.

Chauhan, A.J., Johnston, S.L. 2003. Air pollution and infection in respiratory illness. British Medical Bulletin, 68: 95-112.

Curtis, L., Rea, W., Smith-Willis, P., Fenyves, E., Pan, Y. 2006. Adverse health effects of outdoor pollutants. Environment International, 32: 815830.

Ghorani-Azam, A., Riahi-Zanjani, B., Balali-Mood, M. 2016. Effects of air pollution on human health and practical measures for prevention in Iran. Journal of Research in Medical Science, 21: 65.

Kaldellis, J.K., Kapsali, M., Emmanouilidis, M. 2012. Long-term evaluation of nitrogen oxides and sulphur dioxide emissions from the Greek lignite-based electricity generation sector. Fresenius Environmental Bulletin, 21: 2676-2688.

LTA, 2017. Annual Vehicle Statistics. Motor vehicle population by vehicle type. End of period (year). 2007. 2008. 2009. 2010. 2011. 2012. 2013. 2014. 2015. 2016. 2017. 1 Cars \& Station-wagons. 514, 685. 550, 455. 576, 988. 595, 185. 603, 723.617, 570. 621, 345. 616, 609. 602, 311. 601, 257. 612, 256 i. Land Transport Authority. www.lta.gov.sg/ content/dam/ltaweb/corp/---/

Malakootian, M., Yaghmaeian, K. 2004. Investigation of carbon monoxide in heavy traffic intersections of municipal district. International Journal of Environmental Science and Technology, 1: 227231.

Marilena, K., Elias, C. 2008. Human health effects of air pollution. Environmental Pollution, 151: 362367.

Ndinomholo, H., Caryl, B. 2017. Particulate matter and respiratory symptoms among adults living in Windhoek, Namibia: A cross sectional descriptive study. International Journal of Environmental Research and Public Health, 14: 110.

Raina, P., Mahima, Anshuman, A.G., Anamika, T. 2014. Ambient air quality monitoring and management in Moradabad. International Journal of Sustainable Water and Environmental Systems, 6: 53-59.

Sahoo, D., Dash, A.K., Sahu, S.K. 2017. Ambient air 
quality monitoring and health impact study of air pollution near Joda of Keonjhar, Odisha, India. International Journal Of Engineering Sciences \& Research Technology, 6: 429-434.

Sajjad, H.S., Blond, N., Alain, C., Asif, R., Safdar, A.S., Khadija, S. 2010. Preliminary study of urbanization, fossil fuels consumptions and $\mathrm{CO}_{2}$ emission in
Karachi. African Journal of Biotechnology, 9: 19411948.

Samoli, E., Nastos, P.T., Paliatsos, A.G., Katsouyanni, K., Priftis, K.N. 2011. Acute effects of air pollution on pediatric asthma exacerbation: evidence of association and effect modification. Environmental Research, 111: 418-424. 